\title{
Thoughts on the Integration of Supply Chain of Sporting Goods through Internet of Things
}

\author{
Lin Zhou \\ School of management, Beijing institute of technology, Beijing, China
}

\author{
How to cite this paper: Lin, Z. (2019) Thoughts \\ on the Integration of Supply Chain of Sporting \\ Goods through Internet of Things. International \\ Journal of Humanities, Arts and Social Science, \\ 3(1), 29-31. \\ DOI: $10.26855 /$ jhass.2019.01.001
}

*Corresponding author: Lin Zhou, School of management, Beijing institute of technology, Beijing, China

\begin{abstract}
With the development of the times, the Internet of things is playing an increasingly important role, whose impact on enterprise supply chain is also growing. If the advantages of the Internet of things are efficiently used, enterprises can be promoted to get better development. For the supply chain of sporting goods, the advantages of the Internet of things should be fully utilized. The development of supply chain of sporting goods and Internet of things should be fully combined to make unified requirements for sporting goods and improve infrastructure construction during intermediate links continuously. Although relevant departments have fully realized the importance of the Internet of things, there are still some problems in the specific development process. The imperfect infrastructure and the lack of uniform standards have become important factors affecting the development of supply chain of sporting goods. Only by solving problems constantly, the supply chain can be promoted to have a better development.
\end{abstract}

\section{Keywords}

Internet of things, supply chain management, economic growth

\section{Preface}

With the continuous progress of the society, the Internet of things technology is also developing rapidly and has been widely used in various industries [1,2]. In brief, the Internet of things technology is to realize a positioning global system through Radio Frequency Identification, induction systems and other modes [3]. After combining goods and network together through the positioning global system, the system can monitor and manage the goods at any time [4].

Now, the electronic market is developing continuously. On this background, The Internet of things can improve the application of supply chain of sporting goods to the greatest extent and carry out monitoring and management of the circulation of sporting goods in the largest scope, so as to better change the management mode of supply chain of sporting goods and change the traditional management mode [5]. By changing the management mode, the supply chain of sporting goods can become more perfect and the competitive strength of the user market can be improved to a certain extent. But in the actual process of development, there are still some problems. This kind of technology is still in the initial stage of development. The continuous improvement of technology is the focus of development.

\section{Research Methods}

\subsection{Questionnaire Method}

400 people are sampled from the market and gave out questionnaires through paper and electronic forms in order to better study this problem for clarifying the development direction of the Internet of things integrating supply chain of sporting goods facing the electronic market. The release rate of the questionnaire is $100 \%$. After the survey, 392 questionnaires were recovered among the 400 ones with a recovery rate of $98 \%$ (Table 1). Twelve of the recovered questionnaires were invalid with an effective rate of $95 \%$. The data and information obtained from the effective questionnaires were counted, compared and analyzed. 
Table 1 The Effective Data of Collected Questionnaires (n=380)

\begin{tabular}{|c|c|c|c|c|c|}
\hline Release form & Release number & Recovery number & Effective number & Recovery rate & Total effective rate \\
\hline paper & 400 & 392 & 380 & $98 \%$ & $95 \%$ \\
\hline
\end{tabular}

\subsection{Data Statistic Method}

400 questionnaires were issued and 380 valid questionnaires were collected. The data obtained from the valid questionnaires were counted. SPSS was used for data statistics and analysis to obtain the basic situation of the integration of supply chain of sporting goods through the Internet of things in the electronic market.

\section{Research Results}

\subsection{Development of Supply Chain}

According to relevant data, if the supply chain management mode is used in a scientific and effective way in the development process, the total cost of the enterprise can be reduced by at least $20 \%$, which can save a lot of money for the enterprise. Also, the delivery rate can be increased by at least $15 \%$ for the enterprise on the supply chain. And the production cycle can also be greatly shortened (Table 2).

Table 2 Whether the Development of Supply Chain of Sporting Goods is Reasonable $(n=380)$

\begin{tabular}{lll}
$\begin{array}{l}\text { Whether the Development of Supply Chain } \\
\text { of Sporting Goods is Reasonable }\end{array}$ & Number of People & Percentage \\
\hline Reasonable & 200 & $52.64 \%$ \\
Unreasonable & 180 & $47.36 \%$ \\
\hline
\end{tabular}

\subsection{Meeting the Personalized Needs of Customers Constantly}

Among 380 valid questionnaires (Table 3), 31.52\% of customers feel that their personalized needs are not met and believe that the Internet of things in the electronic market can meet their personalized needs by integrating supply chain of sporting goods. It can be seen that if the Internet of things is used, the problem can be well solved and the visibility of the supply chain can be enhanced, which can improve the transparency of information continuously, fully utilize the resources and use the least cost to get the most benefit.

Table 3 Whether Meeting the Personalized Needs of Customers $(n=380)$

\begin{tabular}{llc}
\hline Whether Meeting the Personalized Needs of Customers & Number of People & Percentage \\
\hline Yes & 260 & $68.42 \%$ \\
No & 120 & $31.52 \%$ \\
\hline
\end{tabular}

\subsection{Imperfect Infrastructure}

According to the data collation in the process of this study, it can be seen that $26.31 \%$ of people think that the infrastructure is imperfect (Table 4). Although there are many advantages in the use of the process of Internet of things devices, there are also some disadvantages, which is there is no way to monitor some remote products.

Table 4 Imperfect Infrastructure $(n=380)$

\begin{tabular}{lll}
\hline Imperfect Infrastructure & Number of People & Percentage \\
\hline Yes & 100 & $26.31 \%$ \\
No & 280 & $72.69 \%$ \\
\hline
\end{tabular}




\section{Discussion and Analysis}

Nowadays, with the education career continuing to evolve, sports have played a very important role in the development of the education career [6]. Therefore, the development of sports will greet a brand new era. As a brand new technology, Internet of things technology must rely on the support of national policies if it wants to achieve better development [7]. Sports have a very good role in promoting the development of students. And the application of Internet of things in integrating supply chain of sporting goods will bring great convenience to the development of sports industry, which means scientific and reasonable use of Internet of things technology has been a general trend [8]. Therefore, the country must issue corresponding policies to support the development of the Internet of things and adopt incentive methods to promote the rapid development of the Internet of things technology.

Above all, if the Internet of things wants to get a better development on the integration of supply chain of sporting goods, it needs continuous improvement in all aspects. The Internet of things industry belongs to a whole new industry, so there are some comparatively austere problemsin the process of the development.Only after these problems are improved, the Internet of things technology can be better developed to promote the constant development of sports undertakings.

\section{References}

[1] Yang, Lili, Shuang-Hua Yang, and Linda Plotnick. "How the internet of things technology enhances emergency response operations." Technological Forecasting and Social Change 80.9 (2013): 1854-1867.

[2] Bo, Li . "Application of Modern IOT Technologies in Sports Material Logistics." Logistics Technology (2013).

[3] Zhang, Zhi, et al. "Code division multiple access/pulse position modulation ultra $\square$ wideband radio frequency identification for Internet of Things: concept and analysis." International Journal of Communication Systems 26.11 (2013): 1502-1502.

[4] Qiao, Libo, GuoMing, and Y. Gong. "Study and Design of Sports Utilities SCM System Based on IOT." Logistics Technology (2013).

[5] Hui, Wang, W. Jing, and R. Wu. "Study and Design of Sports Utility Tracing System Based on IOT." Logistics Technology (2013).

[6] Hastie, Peter A.|Ward, Jeffrey K.|Brock, Sheri J. "Effect of Graded Competition on Student Opportunities for Participation and Success Rates during a Season of Sport Education. " Physical Education \& Sport Pedagogy 22(2016).

[7] Ray, Partha Pratim. "Generic Internet of Things architecture for smart sports." International Conference on Control 2016.

[8] Wilkerson, Gary B., Ashish Gupta, and Marisa A. Colston. "Mitigating sports injury risks using internet of things and analytics approaches." Risk analysis (2018). 